\title{
Costs of reproduction and migration are paid in later return to the colony, not in physical condition, in a long-lived seabird
}

\author{
Marie Claire Gatt ${ }^{1}$ (1) $\cdot$ Maaike Versteegh ${ }^{2} \cdot$ Christina Bauch $^{2} \cdot$ B. Irene Tieleman ${ }^{2} \cdot J^{\prime}$ sé Pedro Granadeiro ${ }^{1}$. \\ Paulo Catry ${ }^{3}$
}

Received: 23 January 2020 / Accepted: 3 October 2020

(c) Springer-Verlag GmbH Germany, part of Springer Nature 2020

\begin{abstract}
Life history theory suggests a trade-off between costly activities such as breeding and migration and somatic self-maintenance. However, how the short-term cost of parental effort is expressed in species with a slow pace-of-life is not well understood. Also, investigating carry-over effects of migration is most meaningful when comparing migratory strategies within the same population, but this has rarely been done. We explore this hypothesis in a long-lived, pelagic seabird, the Cory's Shearwater, Calonectris borealis, where males display partial migration. By manipulating reproductive effort and taking advantage of the natural variation in migratory strategy, we investigate whether early reproductive failure and migratory strategy had implications on the physical condition of males on return to the colony the following year. We experimentally induced breeding failure from mid-incubation, tracked the over-winter movements of these males and of males that invested in parental effort, and assessed innate immunity, stress, and residual body mass the following year. Early breeding failure resulted in earlier return to the colony among all males, associated with greater probability of reproductive success. Residents had a lower tail feather fault bar intensity, an indicator of stress during the non-breeding period, compared to migrants. Reproductive effort and migratory strategy had no impact on physiological condition otherwise. Our results provide evidence that in species with a slow-pace of life, such as the Cory's Shearwater, somatic maintenance is prioritised, with the costs of reproduction and migration paid in delayed arrival date.
\end{abstract}

Keywords Carry-over effects $\cdot$ Fault bars $\cdot$ Life history $\cdot$ Migration $\cdot$ Physiology

Communicated by Thomas Koert Lameris.

This paper advances the knowledge of how K-strategists balance costly annual cycle activities with self-maintenance. Migratory strategies have scarcely been compared at an intra-population level.

Electronic supplementary material The online version of this article (https://doi.org/10.1007/s00442-020-04775-w) contains supplementary material, which is available to authorized users.

Marie Claire Gatt

mcgatt57@gmail.com

1 Centro de Estudos do Ambiente e do Mar (CESAM), Departamento de Biologia Animal, Faculdade de Ciências da Universidade de Lisboa, 1749-016 Lisboa, Portugal

2 Groningen Institute for Evolutionary Life Sciences, University of Groningen, Nijenborgh 7, 9747AG Groningen, The Netherlands

3 Marine and Environmental Sciences Centre (MARE), ISPA-Instituto Universitário, Rua Jardim do Tabaco 34, 1149-041 Lisbon, Portugal

\section{Introduction}

Life history theory states that under conditions of limited resources organisms face a trade-off between energetically expensive activities. One such trade-off reflects the relative importance of current reproductive output against survival and future reproduction. It is often expected that reproductive effort comes at the cost of somatic self-maintenance (Stearns 1992). Since migratory decisions can have energetic consequences, these decisions may also be under energetic trade-offs, within which body condition and immune function may play a mediatory or causative role (Buehler and Piersma 2008; Møller and Szép 2011). The observation of carry-over effects is evidence for the existence of such tradeoffs, where the conditions experienced in one season have effects on fitness and survival in a following season (Harrison et al. 2011).

Recently, the physiological mechanisms that mediate carry-over effects have entered into focus, with hormones, 
oxidative damage, immune function, and metabolic activity among the better studied aspects (Selman et al. 2012; Hegemann et al. 2013, 2015). Results on the physiological basis of carry-over effects across species, however, have been mixed both in terms of the significance and direction of relationships (Lee 2006; Cohen et al. 2009). One potential explanation for this is the effect that life-history strategy has on the nature of trade-offs due to the differing priorities given to current reproductive effort and somatic maintenance by species on different ends of the pace-of-life spectrum (Ricklefs and Wikelski 2002; Lee 2006; Cohen et al. 2009). Seabird families are classically described as having a slow pace-of-life. Studies on carry-over effects in various migratory seabird species have previously found that breeding failure impacts phenology of post-breeding migration (Bogdanova et al. 2011; Catry et al. 2013) and have had mixed results regarding the persistence of these effects into the following year (Bogdanova et al. 2011; Catry et al. 2013; Fayet et al. 2016; Ramos et al. 2018). How environmental conditions outside the breeding period modulate carry-over effects on future fitness in seabirds is not well established.

Partial migration may have consequences on population dynamics since its members are exposed to different conditions in the non-breeding period (Chapman et al. 2011). For instance, arrival body condition and the date of arrival at the breeding grounds influence reproductive output in migratory avian species (Rowe et al. 1994), and both have been reported to carry-over from conditions in the non-breeding area (Inger et al. 2010; Harrison et al. 2011). Moreover, members of a partially migratory population may demonstrate different physiological adaptations to cope with the environments they are routinely exposed to (Hegemann et al. 2015). The non-specific innate immune system acts as a first line of defence against physiological stress, inflammation and infection and is tightly linked to acquired immunity (Berzins et al. 2011). It appears to play a role in energetic trade-offs with migration as it has been found to differ between migrants and residents (Hegemann et al. 2015). Clearly, comparisons of carry-over effects of, and/ or physiological adaptations to, different migratory strategies are most meaningful when it is possible to investigate migratory strategies within the same population. However, such investigations, particularly in species which experience long distance movements within the migratory portion of the population, are not common.

The Cory's Shearwater (Calonectris borealis) is a longlived, partially migratory seabird. In common with other Procellariiformes, both members of a pair participate in the incubation of a single egg and the rearing of the chick during a prolonged breeding season, without the possibility of a second clutch in case of early breeding failure. The majority of the population breeding on Selvagem Grande, Madeira, leaves the breeding colony between October and November and spends the non-breeding period in the Benguela Current in the south-east Atlantic and the adjacent Agulhas Current in the Indian Ocean or other oceanic currents in the southwest and northwest Atlantic, while around a fifth of males remain predominantly resident year round, although some visit secondary wintering areas away from the Canary Current for shorter periods (Dias et al. 2011). Repeated overwinter tracking of individuals reveal that Cory's Shearwaters are largely faithful to a particular non-breeding area, but occasionally utilise different non-breeding areas during their lifetime (Dias et al. 2011, 2013). Residency results in earlier arrival at the colony at the start of the breeding season, which positively affects the probability of a successful breeding attempt and is thought to be the evolutionary driver for overwinter residency in males (Catry et al. 2013; Perez et al. 2014). Individuals that remain resident have previously been recorded to experience lower corticosterone levels over winter compared to migrants (Pérez et al. 2016). However, whether this difference is a reflection of underlying body condition is not known.

Here, we investigate the role of physical condition in the carry-over effects of reproductive effort and migratory strategy in a population of Cory's Shearwater breeding on Selvagem Grande. We experimentally manipulated reproductive effort in a group of males, the partially migratory sex, by inducing breeding failure during incubation and subsequently tracked these and males that invested in parental effort over winter using light-level geolocation (GLS). We then assessed size-corrected body mass, nitric oxide concentration (NOx), plasma concentration of haptoglobin, natural antibody and complement activity (hemagglutinationhemolysis), and tail feather fault bar intensity as proxies of physical condition on arrival to the colony after return migration. Using these data, we investigated whether early (experimentally induced) reproductive failure and migratory strategy had implications on physical condition on return.

We expect that the early relief of breeding duties, earlier than in previous similar experimental set-ups (Catry et al. 2013), should influence the energy budget available to Cory's Shearwaters during the breeding period due to reduced parental effort. The maintenance of the non-specific innate immune system (haptoglobin, hemagglutinationhemolysis), long-term stress (fault bar intensity) and inflammation (NOx, haptoglobin) markers, size-corrected body mass and/or date of return to the colony the following year should differ between experimental and control groups if the costs of reproductive effort persist over the non-breeding season as carry-over effects in body condition (Owen-Ashley and Wingfield 2007; Buehler et al. 2010). These indices of body condition should also reflect the migratory strategy of Cory's Shearwaters if habitat quality, exposure to infection, and/or intrinsic adaptations (in the case of innate immunity) differ substantially between migrants and residents over the 
non-breeding season (Hegemann et al. 2012; Nwaogu et al. 2019).

\section{Materials and methods}

\section{Study site and sample collection}

Selvagem Grande (Lat 30.140 N, Long 15.869 W) is an island nature reserve located ca. $300 \mathrm{~km}$ south of the Madeiran Archipelago, Portugal. Around 30,000 pairs of Cory's Shearwaters breed on the island. A sub-population is the subject of long-term research, with the vast majority of individuals ringed, of known or approximated age, known sex, and measured (culmen length, bill height at base, bill height at gonys, and wing length) (Granadeiro et al. 2006). Cory's Shearwaters return to their nest burrows after the non-breeding season between mid-February and early April to undertake a long period of nest defence and mating before laying a single egg in early June, which they incubate for around 2 months (Zino et al. 1987). The chick rearing season lasts until around November, with adults leaving the colony to spend the non-breeding season at sea in discrete nonbreeding areas (Catry et al. 2011). Individual reproductive success is recorded annually in this population, with observations carried out early in the incubation period and in the late chick-rearing period.

Between the end of June and early July 2017, around 1 month after laying and 1 month before hatching, 25 nests were selected for egg removal to experimentally induce breeding failure during incubation. These nests were selected to represent males of a variety of ages and both successful and unsuccessful breeders from the previous breeding season. These males (the "experimental group") were fitted with leg-mounted geolocation devices (GLS, Migrate Technology model C330) to record their overwinter movements. The total weight of the deployment was well below $1 \%$ of the birds' body weight and can be assumed to bear minimal or no effects on survival and fitness (Bodey et al. 2017). This method resulted in an $88 \%$ retrieval rate in 2018 , consistent with the rate of return of breeding birds from one year to the next (Mougin et al. 1997). From a pool of 80 males also GLS-tracked over the same winter as part of a different investigation, we selected 24 which successfully reproduced in 2017, with an age distribution similar to the males in the experimental group, to serve as the "parental effort" group for comparisons of carry-over effects of reproductive effort.

In 2018 nest attendance was checked daily between midFebruary and mid-April to encounter GLS-equipped birds on their first day after return migration. GLS data confirms that Cory's Shearwaters fly directly to the colony and their nest on arrival from migration. Males that formed part of the experimental and parental effort groups were extracted from their nest burrows by hand, were weighed (to the nearest $10 \mathrm{~g}$ ) using a spring balance and between $1 \mathrm{ml}$ and $1.5 \mathrm{ml}$ of blood were collected from the brachial vein using a syringe flushed with heparin prior to use. The duration of manipulation lasted a maximum of $15 \mathrm{~min}$. The collected whole blood was centrifuged and the resulting plasma frozen at $-20{ }^{\circ} \mathrm{C}$ until analysed. These procedures were carried out within a few hours of blood collection. Non-breeding destination was assigned from the GLS positional data, comparing to core utilisation distributions described for this population (Catry et al. 2011; Dias et al. 2011, 2012b; Perez et al. 2014) (Fig. 1).

During the incubation period of 2018, the same birds were reencountered as part of annual nest monitoring and tail feather fault bar intensity was assessed. Fault bars are translucent bands along the breadth of a feather that are produced by low keratin deposition during feather growth as a result of acute stress events, such as inclement weather and negative inter-individual interactions. These can range in severity from faint bars to extreme keratin depletion resulting in feather breakage (Jovani and Rohwer 2016). Tail feathers experience lower canalisation against fault bars compared to more functionally important feathers to flight, such as remiges, therefore, are better suited to reflect experienced stress (Bortolotti et al. 2002; Boonekamp et al. 2017). In Cory's Shearwaters, tail feathers start moulting at the end of the breeding season and most of the population completes tail moult by their return to the colony (Alonso et al. 2009). Therefore, fault bars integrate stress mostly experienced over the non-breeding period and are a cheap, minimally invasive method to obtain data on long-term stress. Due to the presence of feathers broken at fault bars, the number of affected tail feathers, rather than the total number of fault bars, is considered here as fault bar intensity (Bortolotti et al. 2002). Characterising the severity of fault bars has not been shown to provide additional information (Boonekamp et al. 2017).

\section{Physical condition indices}

Residual body mass (body mass corrected for body size) is often used as an index of nutritional body condition shown to correlate with health status and reproductive performance (Green 2001; Gómez-Díaz et al. 2008). Body size was estimated by inputting biometric measurements (culmen length, bill height at base, bill height at gonys, and wing length) into a principal component analysis. Residual body mass was obtained by extracting the residuals from a regression between mass and the resulting first principle component (Bortolotti et al. 2002).

The plasma samples were analysed for haptoglobin concentration, hemolysis and hemagglutination scores, and nitric oxide concentration at the Groningen Institute for Evolutionary Life Sciences, University of Groningen, The 
Fig. 1 Cory's Shearwaters spend the non-breeding season in discrete ocean currents, either remaining resident in the Canary Current (blue), or migrating to currents off southern Africa (yellow), to the southwest Atlantic (red) or the northwest Atlantic (orange). Pie charts represent the number of males wintering in each location that either had their previous reproductive effort experimentally reduced (experimental group, empty segments) or were naturally successful (parental effort group, filled segments). The colony location is denoted by the solid diamond. Different shapes represent the positional data (GLS) of six different individuals between December and February

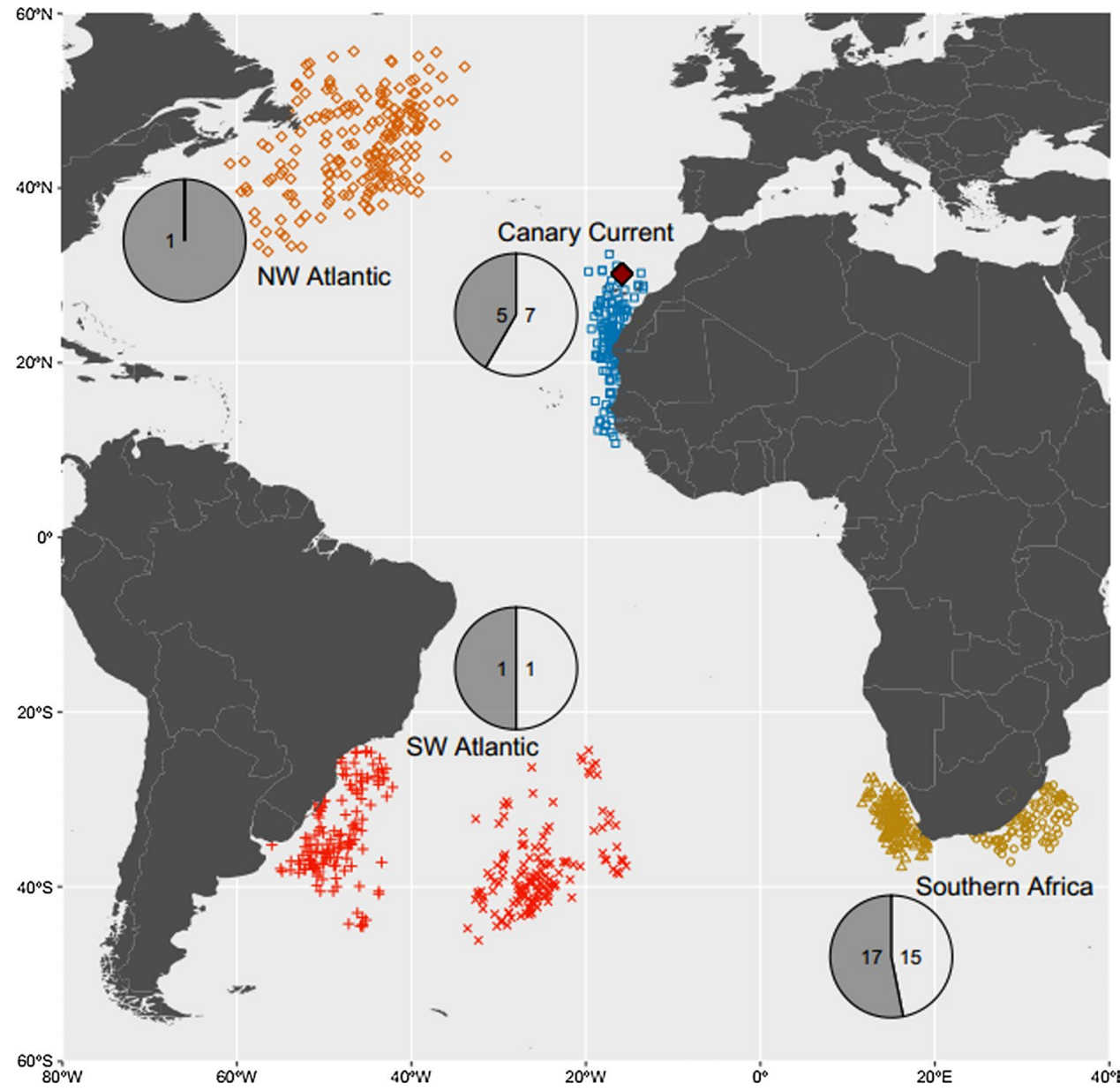

Netherlands. Haptoglobin is an acute phase protein that responds to acute infection, inflammation, or trauma with a marked and rapid increase in concentration in the blood (Matson et al. 2012). We quantified haptoglobin $\left(\mathrm{mg} \mathrm{ml}^{-1}\right)$ using the manual method of a commercially-available colorimetric functional assay (TP801; Tri-Delta Diagnostics, NJ, USA), with adjustments described in Matson et al. (2012), measuring absorbances at two wave-lengths: a scan at $450 \mathrm{~nm}$, taken before the last reagent was added, to measure the redness of the plasma samples, and a scan at $630 \mathrm{~nm}$ representing the concentration of haptoglobin in the plasma. A hemolysis/hemagglutination assay, as described in Matson et al. (2005), assesses nonspecific natural antibodies (agglutination score) and natural antibodymediated complement activation (lysis score) to monitor responses of innate immune system (Matson et al. 2005). The plasma concentration of nitric oxide, a multifunctional signalling molecule with roles in the neural system and the inflammation process of the non-specific immune system (Sild and Hõrak 2009), was obtained by quantifying total plasma nitrite and nitrate concentration $(\mathrm{NOx}, \mu \mathrm{M})$ following the methods described in Sild and Hõrak (2009).

\section{Statistical analysis}

Statistical analyses were performed with R Statistical Package, version 3.5.1 (R Core Team 2019). We first tested whether male arrival date at the colony in 2018 was related to subsequent probability of securing a nest and incubating an egg ('laying success'; $1=$ egg present during the incubation period of 2018, $0=$ no egg recorded in nest), considering the males from the parental effort group, the experimentally manipulated males, and an additional 30 males that were also tracked overwinter and whose age was known $(n=70)$ to increase statistical power. We ran a generalised linear model (function "glm") with a binomial error structure relating laying success against the date of return to the colony and age.

We ran a chi-squared test to confirm that experimental and parental effort groups did not differ significantly in the migratory strategies represented by each.

We assessed the effects of previous reproductive effort and migratory strategy on (i) subsequent date of return to the colony in male Cory's Shearwaters, (ii) haptoglobin concentration, (iii) lysis and (iv) agglutination scores, (v) 
NOx, (vi) residual body mass, and (vii) fault bar intensity separately. We compared Akaike's Information Criterion adjusted for small sample sizes (AICc) and Akaike weights (Burnham and Anderson 2002) for all possible (generalised) linear models (functions "lm", "glm"; function "dredge", package MuMIn) for each dependent variable, including main effects reproductive effort and migratory strategy and the interaction term between them. In the analysis of haptoglobin, redness as measured at $450 \mathrm{~nm}$ was kept in all models as a covariate, and statistics are not reported. Migratory strategy was treated as a binary value differentiating between individuals that spent the non-breeding period largely resident in the Canary Current and those that migrated to the Benguela and Agulhas Currents off South Africa, the SW Atlantic, or the NW Atlantic for the entirety of the non-breeding period. In models investigating date of return to the colony we used a more conservative definition of migratory strategy, where we differentiated between individuals that remained resident year-round from those that migrated or carried out shorter large-scale movements during the non-breeding period (see below) due to the expected effects even shorter movements have on arrival date. Age was not included in these models since the experimental and parental effort groups contained males of similar age groups and its inclusion in a linear model was not found to improve the model predictability (but see Appendix S1 of the Electronic Supplementary Material). Haptoglobin concentration, lysis score, and NOx were modelled with a gamma error distribution, while fault bar intensity was modelled with a Poisson error distribution. The best supported model was considered to be that with the lowest AICc, with models with a difference in AICc $(\triangle \mathrm{AICc})$ smaller than 2 considered competitive. In these cases, a model averaging approach was carried out to obtain model-averaged parameter estimates (function "model.avg", package MuMIn) (Burnham and Anderson 2002). Sample sizes are in Table 1.

To control for any possible effect of individual quality, we repeated the analyses of the effects of migratory strategy and reproductive effort comparing males from the experimental group with a control group of males of similar ages selected at the same time as the egg-removal, containing both naturally successful and naturally failed breeders. This is presented in Appendix S2 of the Electronic Supplementary Material.

Of the 12 males that did not leave the Canary Current after the breeding season, four spent between 8 and 16 days at a secondary wintering area in the South Atlantic and one carried out a large loop flight to the South Atlantic prior to returning to the colony. For this reason, it is not possible to isolate differences in body condition that result from migratory flight due to the small number of individuals that did not undertake long-distance movements.
Table 1 The classification of male Cory's Shearwaters in terms of reproductive effort (experimental vs the naturally successful parental effort group) and migratory strategy (resident or migratory) for each of the models assessing the carry-over effects of reproductive effort and migratory strategy on physical condition and date of return to the colony

\begin{tabular}{|c|c|c|c|c|}
\hline & \multicolumn{2}{|c|}{ Experimental } & \multicolumn{2}{|c|}{ Successful } \\
\hline & Resident & Migratory & Resident & Migratory \\
\hline Haptoglobin $(n=45)$ & 7 & 16 & 5 & 17 \\
\hline Lysis $(n=47)$ & 7 & 16 & 5 & 19 \\
\hline Agglutination $(n=47)$ & 7 & 16 & 5 & 19 \\
\hline NOx $(n=38)$ & 7 & 12 & 5 & 14 \\
\hline $\begin{array}{l}\text { Residual body mass } \\
\quad(n=45)\end{array}$ & 7 & 15 & 5 & 17 \\
\hline $\begin{array}{l}\text { Fault bar intensity } \\
\qquad(n=41)\end{array}$ & 7 & 12 & 5 & 17 \\
\hline Arrival at nest $(n=47)$ & 3 & 16 & 4 & 19 \\
\hline
\end{tabular}

The sample size in each model is denoted by $n$.

Statistical estimates are represented with their standard error $(\mathrm{Est} \pm \mathrm{SE})$.

\section{Results}

None of the males tracked between 2017 and 2018 for which overwinter movements of the previous year are known (unpublished data) changed migration destination, including 20 males whose reproductive effort was experimentally reduced. This suggests that the manipulation of reproductive effort did not influence migratory decision. This allows us to disentangle the potential concurrent effects of reproductive effort and migratory strategy. The non-breeding destinations of males of both experimentally induced reproductive failure and natural reproductive success are displayed in Fig. 1. The distribution of migratory destinations between the two groups does not differ significantly $\left(\chi^{2}=1.44, d f=3\right.$, $p=0.697)$.

Early arrival at the colony in 2018 in males was significantly related to an increased probability of securing a nest and incubating an egg within our sample of 70 males (GLM: Est $=-0.07 \pm 0.03, z=-2.83, p=0.005)$. Age had no significant effect on laying success (GLM: Est $=-0.02 \pm 0.05$, $z=-0.45, p=0.653$ ).

Male Cory's Shearwaters whose reproductive effort was experimentally reduced returned to the colony earlier the following year compared to males investing in parental effort (Est $=6.72 \pm 2.96$ days; Fig. 2 ). As has been previously reported (Perez et al. 2014), residents returned to the colony earlier than migrants (Est $=16.48 \pm 3.95$ days). There was no evidence for an interactive effect between reproductive effort and migratory strategy (Table 2). 
Fig. 2 Male Cory's Shearwaters that were relieved of breeding duties during incubation in 2017 (experimental group, yellow) returned earlier to the colony on Selvagem Grande the following spring compared to males from the parental effort group (blue) that raised a chick. Males that spent the non-breeding season resident in the Canary Current returned earlier than migrants. Sample sizes are indicated above each box

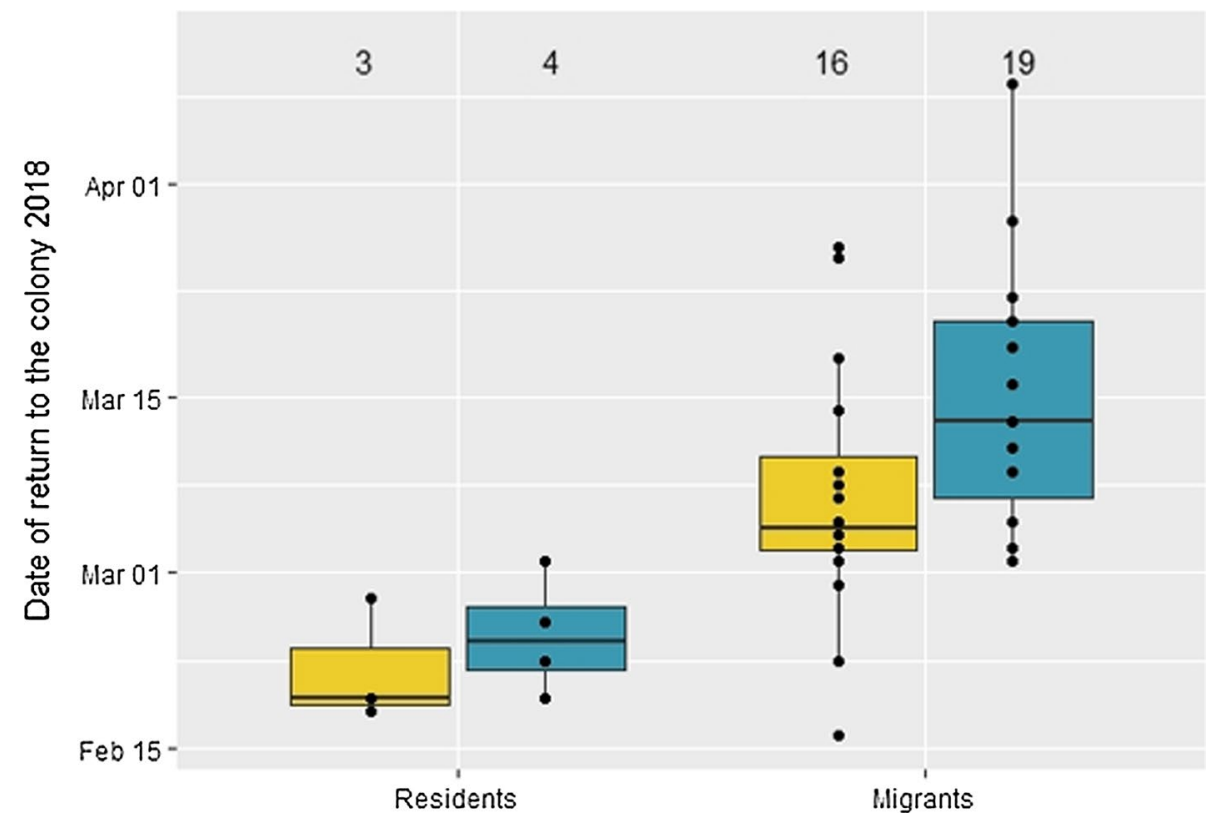

Null models, including no explanatory variables, were the best supported models for haptoglobin concentration, lysis and agglutination scores, and NOx (Table 2). Migratory strategy and previous reproductive effort featured in models explaining haptoglobin concentration and lysis and agglutination scores, which had a $\Delta \mathrm{AICc}<2$. However, the model averaged estimates and standard errors of these variables suggested that their effect on the immune indices was likely negligible (Tables 2,3 ). The mean values of indices of physical condition found in this population are presented in Appendix S3 of the Electronic Supplementary Material.

The null model was also the best supported model explaining residual body mass, although all possible models returned a $\triangle \mathrm{AICc}<2$ and were considered competitive models (Table 2; see also ESM). However, the estimates and standard errors of the explanatory variables suggest that none of them had a strong effect on residual body mass on return to the colony (Table 3, Fig. 3).

Males that migrated had more tail feathers affected by fault bars than those that remained resident (Table 3, Fig. 4).

Using a control group of males of mixed reproductive outcomes in 2017 instead of a group of only (naturally) successful males did not change the model results (see Appendix S2 of the Electronic Supplementary Material).

\section{Discussion}

Our results illustrate the ways in which a long-lived seabird with a slow pace of life balances the costs of annual activities. We show how Cory's Shearwaters with different previous reproductive effort and migratory strategy return to the colony in similar physiological condition, as reflected by a broad selection of parameters, and that costs are paid in phenological differences, while somatic maintenance is prioritised.

\section{Life history and carry-over effects from reproduction}

The results from our experimental manipulation of reproductive effort demonstrate that the cost of such effort incurred in Cory's Shearwaters is largely reflected in their arrival date rather than their physiological state on return from migration. The primary explanation for these observations is that somatic maintenance is prioritised in K-strategists as future survival and reproductive potential are favoured over current reproductive output (Stearns 1992). Analysis of telomere shortening, a biomarker for ageing, within the same experimental set-up also support these observations as manipulated reproductive effort had no significant impact on telomere length from 1 year to the next (Bauch et al. 2020). The cost for self-maintenance appears to be paid by delaying arrival date, as reflected by the earlier arrival of males whose reproductive effort was experimentally reduced, irrespective of migratory strategy. Despite the lower sample sizes available for this comparison in arrival date, the results obtained are in agreement with previous observations in this colony (Catry et al. 2013). In this population, the date of arrival at the colony can influence reproductive success (Catry et al. 2013; Perez et al. 2014, this paper). Therefore, in some years and under certain environmental conditions a delayed arrival may result in a missed breeding attempt. 
Table 2 AICc values and AICc weights for the selection of (generalised) linear models assessing the effects of reproductive effort and/or migratory strategy on date of return to the colony and physical condition indices in male Cory's Shearwaters

\begin{tabular}{|c|c|c|c|c|c|}
\hline Dependent variable & Model & $\mathrm{K}$ & $\mathrm{AICc}$ & $\Delta \mathrm{AICc}$ & AICc weights \\
\hline \multirow[t]{5}{*}{ (i) Arrival at nest } & Rep. + Mig. Strat & 3 & 314.6 & $\mathbf{0}$ & 0.63 \\
\hline & Rep. $\times$ Mig. Strat & 4 & 316.7 & 2.18 & 0.211 \\
\hline & Mig. Strat & 2 & 317.3 & 2.77 & 0.157 \\
\hline & Rep & 2 & 327.6 & 13.06 & 0.001 \\
\hline & Null model & 1 & 328.7 & 14.14 & 0.001 \\
\hline \multirow[t]{10}{*}{ (ii) Haptoglobin } & Null model & 2 & -65 & $\mathbf{0}$ & 0.488 \\
\hline & Mig. Strat & 3 & -63.3 & 1.74 & 0.205 \\
\hline & Rep & 3 & -63 & 2.05 & 0.175 \\
\hline & Rep. + Mig. Strat & 4 & -61.2 & 3.82 & 0.072 \\
\hline & Rep. $\times$ Mig. Strat & 5 & -60.8 & 4.22 & 0.059 \\
\hline & Null model & 1 & 48.4 & $\mathbf{0}$ & 0.511 \\
\hline & Rep & 2 & 50.2 & 1.81 & 0.207 \\
\hline & Mig. Strat & 2 & 50.5 & 2.17 & 0.173 \\
\hline & Rep. + Mig. Strat & 3 & 52.4 & 4.03 & 0.068 \\
\hline & Rep. $\times$ Mig. Strat & 4 & 53.4 & 5.04 & 0.041 \\
\hline \multirow[t]{5}{*}{ (iv) Agglutination } & Null model & 1 & 118.2 & $\mathbf{0}$ & 0.463 \\
\hline & Rep & 2 & 119.5 & 1.34 & 0.237 \\
\hline & Mig. Strat & 2 & 120.1 & 1.89 & 0.18 \\
\hline & Rep. + Mig. Strat & 3 & 121.6 & 3.45 & 0.082 \\
\hline & Rep. $\times$ Mig. Strat & 4 & 123.2 & 5.01 & 0.038 \\
\hline \multirow[t]{5}{*}{ (v) $\mathrm{NOx}$} & Null model & 1 & -348.2 & $\mathbf{0}$ & 0.551 \\
\hline & Rep & 2 & -346 & 2.16 & 0.187 \\
\hline & Mig. Strat & 2 & -346 & 2.19 & 0.184 \\
\hline & Rep. + Mig. Strat & 3 & -343.8 & 4.44 & 0.06 \\
\hline & Rep. $\times$ Mig. Strat & 4 & -341.4 & 6.85 & 0.018 \\
\hline \multirow[t]{5}{*}{ (vi) Residual body mass } & Null model & 1 & 349.8 & $\mathbf{0}$ & 0.296 \\
\hline & Mig. Strat & 2 & 350.4 & 0.52 & 0.228 \\
\hline & Rep. + Mig. Strat & 3 & 351 & 1.14 & 0.168 \\
\hline & Rep & 2 & 351.1 & 1.28 & 0.156 \\
\hline & Rep. $\times$ Mig. Strat & 4 & 351.2 & 1.34 & 0.152 \\
\hline \multirow[t]{5}{*}{ (vii) Fault bar intensity } & Mig. Strat & 2 & 187.8 & $\mathbf{0}$ & 0.497 \\
\hline & Rep. + Mig. Strat & 3 & 189.1 & 1.25 & 0.266 \\
\hline & Rep. $\times$ Mig. Strat & 4 & 189.5 & 1.71 & 0.212 \\
\hline & Null model & 1 & 195.1 & 7.27 & 0.013 \\
\hline & Rep & 2 & 195.1 & 7.28 & 0.013 \\
\hline
\end{tabular}

Models in bold are equally supported by the data $(\Delta \mathrm{AICc}<2)$

$K$ number of estimable parameters including the intercept
The implication of not carrying the somatic costs of reproduction into the following year is that Cory's Shearwaters "settle the bill" over the non-breeding period. Previous phenological analyses have shown that the delayed return to the colony of successful breeders is a result of spending a longer time in the wintering area (Catry et al. 2013). Cory's Shearwaters spend large proportions of time resting on the water in the non-breeding season compared to the breeding season (Ramos et al. 2018). While this has been associated with low flight activity during moult in some seabirds (Cherel et al. 2016), it may also suggest that there is a low energy requirement associated with spending the non-breeding period in highly productive waters (Péron et al. 2010). This could explain the delay in successful breeders to return to the colony, as they spend more time in the nonbreeding area, where somatic maintenance can take place.

A lack of detectable carry-over effects of reproductive effort on body condition has been found in other seabirds (Great Skua Stercorarius skua: Bourgeon et al. (2014); Leach's Storm-petrel Oceanodroma leucorhoa: Gilmour et al. 2014; Manx Shearwater Puffinus puffinus: Fayet et al. 2016)). Interestingly, while experimental manipulations decreasing parental effort in seabirds often do not have consequences on physical condition and/or future reproductive 
Table 3 Model-averaged parameter estimates, their standard errors $( \pm$ SE), and 95\% confidence intervals (CI), calculated across models considered competitive $(\Delta \mathrm{AICc}<2)$

\begin{tabular}{llcrr}
\hline Dependent variable & Independent variables & Est \pm SE & \multicolumn{2}{l}{$95 \%$ CI } \\
\cline { 4 - 5 } & & & Lower & Upper \\
\hline Haptoglobin & Mig. Strat & $0.36 \pm 0.44$ & -0.53 & 1.25 \\
Lysis & Rep & $0.04 \pm 0.06$ & -0.08 & 0.15 \\
Agglutination & Mig. Strat & $-0.17 \pm 0.28$ & -0.73 & 0.39 \\
& Rep & $-0.23 \pm 0.24$ & -0.71 & 0.25 \\
Residual body mass & Mig. Strat & $-40.85 \pm 28.62$ & -98.64 & 16.94 \\
& Rep & $10.29 \pm 32.03$ & -54.24 & 74.81 \\
Fault bar intensity & Mig. Strat $\times$ Rep & $63.89 \pm 41.29$ & -20.69 & 148.48 \\
& Mig. Strat & $0.57 \pm 0.28$ & 0.02 & 1.12 \\
& Rep & $-0.06 \pm 0.42$ & -0.89 & 0.77 \\
\hline
\end{tabular}

See Table 2 and methods for more details
Fig. 3 Residual body mass of male Cory's Shearwaters on return to the colony as classified by migratory strategy and by previous reproductive effort (experimental group, yellow, vs parental effort group, blue). Sample sizes are indicated above each box

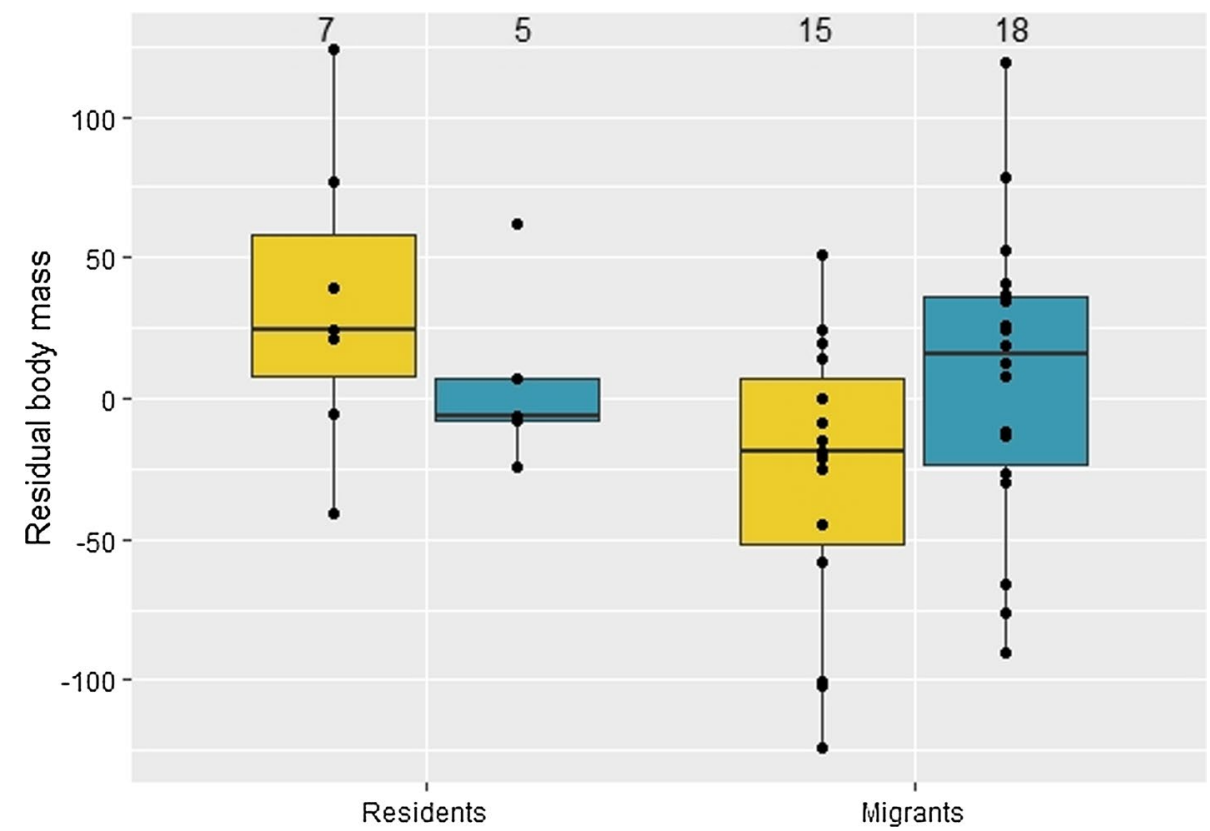

success, those increasing provisioning duration of chicks (Fayet et al. 2016) or clutch size (Berzins et al. 2011) did, and the negative effects of increased reproductive effort have also been seen in other avian groups (Santos and Nakagawa 2012). This suggests that one could expect carry-over effects from the cost of reproduction to manifest in years with adverse environmental conditions which elevate the usual cost of successfully completing a breeding attempt.

Our results on the effects of relaxation of parental duties on physical condition conform to previous studies on the same colony of Cory's Shearwaters on Selvagem Grande (Catry et al. 2013; Perez et al. 2014) as well as to aspects from a similar study on Cory's Shearwater from Gran Canaria (Ramos et al. 2018), but also highlight strong year effects or possible colony-specific differences. Data from two colonies suggest that reproductive success in 1 year does not influence reproductive success in the following year (Catry et al. 2013; Ramos et al. 2018). However, the relationships of reproductive success with arrival date and over-winter stress levels may be colony-specific. While inducing breeding failure during either incubation (this study) or chick rearing (Catry et al. 2013) resulted in earlier return to the Selvagem Grande colony the following year, this was not the case for birds breeding on Gran Canaria (Ramos et al. 2018). The impact of arrival date on reproductive success has been established in the Selvagem Grande population and probably stems from the very large size of the colony, causing high intra-specific competition for good quality nesting sites which in turn results in common fights between males on arrival to the colony (Ramos et al. 1997; Catry et al. 2013; pers. observ.), which could be less intense on Gran Canaria. Additionally, Cory's Shearwaters from 
Fig. 4 Number of tail feathers affected by fault bars in Cory's Shearwaters was significantly lower in males that remained resident in the Canary Current than in males that migrated to the Benguela and Agulhas currents. Sample sizes are indicated above each box

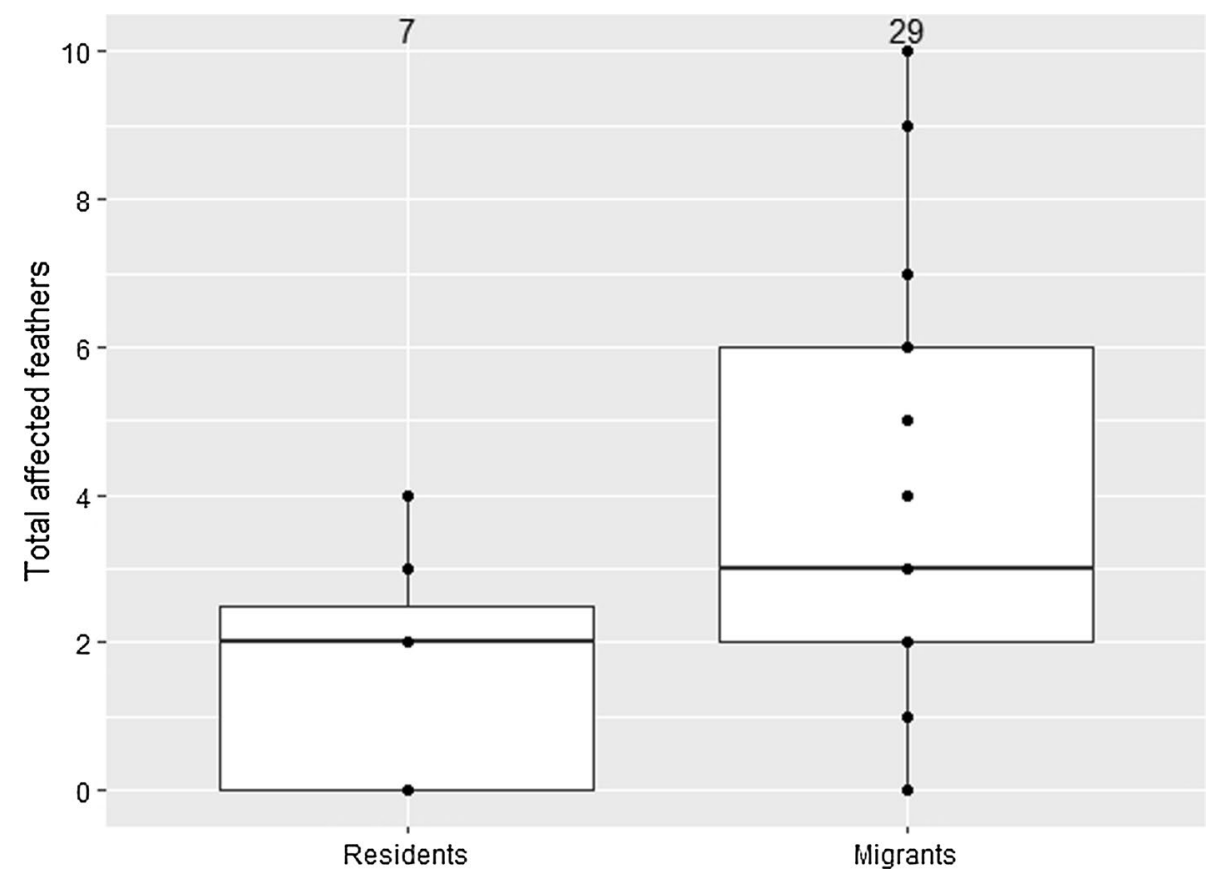

the Gran Canaria colony experienced increased stress levels during the non-breeding period after experiencing higher reproductive effort (Ramos et al. 2018), but this was not the case in birds breeding on Selvagem Grande as investigated over two separate years using different stress markers (Catry et al. 2013; this study). Ramos et al. (2018) suggest that corticosterone may mediate the impacts of reproductive effort on traits such as haematological health state. However, we found no evidence for this in the current study. The lack of a detectable relationship of reproductive success between years despite consequences in arrival date in the system on Selvagem Grande is probably due to the greater complexity of the system and the additional role of other confounding factors which cannot be controlled or easily accounted for.

\section{Costs of migratory strategy}

Migratory strategy significantly determines overwinter stress levels for birds breeding on Selvagem Grande, reflected in both feather corticosterone levels (Perez et al. 2014) as well as fault bar intensity (this study), two markers known to correlate within a feather (Bortolotti et al. 2009). This difference in experienced stress between nonbreeding areas was not seen in birds breeding on Gran Canaria (Ramos et al. 2018). The lower stress levels recorded in residents compared to migrant males could allude to residents experiencing better conditions overwinter. However, such differences do not appear to translate into long-term physiological changes, as evidenced by the similarity between residents and migrants in haematological measurements, again suggesting a great ability at somatic maintenance. An alternative explanation could be that within the population on Selvagem Grande resident males have a lower propensity to stress compared to migrants due to a separation in coping styles (Koolhaas et al. 1999). Investigations of behavioural differences between migrants and residents during the breeding season suggest that this may indeed be the case (M. Gatt et al. unpublished data).

Innate immunity, while strongly related to acquired immunity, is genetically mediated (Matson et al. 2005) and may vary seasonally in relation to the environmental changes to which a population is adapted (Hegemann et al. 2012; Versteegh et al. 2014). Differences in innate immune parameters have been found between migrants and residents from 1 year to the next in Skylarks which, like Cory's Shearwaters, show individual flexibility in their migratory strategy (Hegemann et al. 2015). The similarity reported here between Cory's Shearwaters of different migratory strategies could suggest that the larger proportion of the annual cycle spent in the common breeding ground (Catry et al. 2011) may have a greater influence on innate immune function, both in terms of genetic adaptation and of infection and inflammation risk, than the period spent in separate non-breeding areas.

The long-distance movements undertaken by a number of predominantly resident birds preceding their return to the colony complicates an analysis of the cost of longdistance migratory flight in this system. Dynamic soaring flight performed by shearwaters and their ability to feed $e n$ route would suggest that migratory flight should not be very costly (Dias et al. 2012a). Indeed, perhaps the observation of Cory's Shearwaters undertaking trans-oceanic flights over a 
few days just before returning to the breeding ground could also be evidence to this.

In conclusion, our data suggest that demanding annual cycle events in Cory's Shearwaters do not result in depleted physical condition carrying over into the following breeding season. Instead, delayed arrival at the colony perhaps serves to continue processes of somatic maintenance during the less energy expensive non-breeding period, which secures survival but can potentially have negative consequences on future breeding potential. While the causes of differences in stress response with migratory strategy are yet to be uncovered, these also do not appear to integrate into lasting physiological effects.

Acknowledgements We are grateful to Filipe Moniz, Pedro Melo, and all helpers for assistance in the field in this long-term project, Merijn Driessen for support in the lab at the Groningen Institute for Evolutionary Life Sciences, and Sara Pardal for advice in early planning. Instituto das Florestas e da Conservação da Natureza gave permissions and support for the work on Selvagem Grande. Procedures were approved by ISPA's Ethical Committee for Animal Welfare and carried out under licenses issued by the DGAV (Direção Geral de Alimentação e Veterinária), license number DGAV 0421/2017, and by the Instituto das Florestas e da Conservação da Natureza, IFCN licence 1/S (2017). Funding was provided by the Fundação para a Ciência e a Tecnologia (FCT, Portugal) through projects Seamigrant PTDC/BIAANM/3743/2014 and Oceanwebs (PTDC/MARPRO/0929/2014), and $\mathrm{PD} / \mathrm{BD} / 127807 / 2016$ awarded to MCG. Thanks are due for the financial support to CESAM (UIDB/50017/2020 and UIDP/50017/2020) and MARE (UIDB/04292/2020 and UIDP/04292/2020) by FCT, Portugal.

Author contribution statement PC and JPG conceived the longterm monitoring scheme. MCG, PC and JPG developed the ideas and designed the study. MCG and CB carried out the fieldwork. MCG led the writing of the manuscript. BIT provided logistical support for the analyses of immune parameters. MCG and MAV analysed and interpreted the immune data. All authors contributed critically to the drafts and gave final approval for publication.

\section{References}

Alonso H, Matias R, Granadeiro JP, Catry P (2009) Moult strategies of Cory's Shearwaters Calonectris diomedea borealis: the influence of colony location, sex and individual breeding status. J Ornithol 150:329-337. https://doi.org/10.1007/s10336-008-0354-2

Bauch C, Gatt MC, Granadeiro JP et al (2020) Sex-specific telomere length and dynamics in relation to age and reproductive success in Cory's Shearwaters. Mol Ecol 29:1344-1357. https://doi. org/10.1111/mec.15399

Berzins LL, Gilchrist HG, Matson KD, Burness G (2011) Sex-specific effects of increased incubation demand on innate immunity in Black Guillemots. Physiol Biochem Zool 84:222-229. https://doi. org $/ 10.1086 / 658373$

Bodey TW, Cleasby IR, Bell F et al (2017) A phylogenetically controlled meta-analysis of biologging device effects on birds: deleterious effects and a call for more standardized reporting of study data. Methods Ecol Evol 9:946-955. https://doi.org/10.1111/ ijlh.12426
Bogdanova MI, Daunt F, Newell M et al (2011) Seasonal interactions in the Black-legged Kittiwake, Rissa tridactyla: links between breeding performance and winter distribution. Proc R Soc B Biol Sci 278:2412-2418. https://doi.org/10.1098/ rspb.2010.2601

Boonekamp JJ, Dijkstra R, Dijkstra C, Verhulst S (2017) Canalization of development reduces the utility of traits as fitness biomarkers: feather fault bars in nestling birds. Funct Ecol 31:719-727. https://doi.org/10.1111/1365-2435.12765

Bortolotti GR, Dawson RD, Murza GL (2002) Stress during feather development predicts fitness potential. J Anim Ecol 71:333342. https://doi.org/10.1046/j.1365-2656.2002.00602.x

Bortolotti GR, Marchant T, Blas J, Cabezas S (2009) Tracking stress: localisation, deposition and stability of corticosterone in feathers. J Exp Biol 212:1477-1482. https://doi.org/10.1242/ jeb. 022152

Bourgeon S, Leat EHK, Magnusdóttir E et al (2014) Feather corticosterone levels on wintering grounds have no carry-over effects on breeding among three populations of Great Skuas (Stercorarius skua). PLoS ONE 9:1-6. https://doi.org/10.1371/journ al.pone.0100439

Buehler DM, Piersma T (2008) Travelling on a budget: predictions and ecological evidence for bottlenecks in the annual cycle of longdistance migrants. Philos Trans R Soc B Biol Sci 363:247-266. https://doi.org/10.1098/rstb.2007.2138

Buehler DM, Tieleman BI, Piersma T (2010) How do migratory species stay healthy over the annual cycle? A conceptual model for immune function and for resistance to disease. Integr Comp Biol 50:346-357. https://doi.org/10.1093/icb/icq055

Burnham KP, Anderson DR (2002) Model selection and multimodel inference: a practical information-theoretic approach, 2nd edn. Springer, New York, New York

Catry P, Dias MP, Phillips RA, Granadeiro JP (2011) Different means to the same end: long-distance migrant seabirds from two colonies differ in behaviour, despite common wintering grounds. PLoS ONE 6:4-9. https://doi.org/10.1371/journal.pone.0026079

Catry P, Dias MP, Phillips RA, Granadeiro JP (2013) Carry-over effects from breeding modulate the annual cycle of a long-distance migrant: an experimental demonstration. Ecology 94:1230-1235. https://doi.org/10.1890/12-2177.1

Chapman BB, Brönmark C, Nilsson J-Å, Hansson L-A (2011) The ecology and evolution of partial migration. Oikos 120:1764-1775. https://doi.org/10.1111/j.1600-0706.2011.20131.x

Cherel Y, Quillfeldt P, Delord K et al (2016) Combination of at-sea activity, geolocation and feather stable isotopes documents where and when seabirds molt. Front Ecol Evol. https://doi.org/10.3389/ fevo.2016.00003

Cohen AA, Mauck RA, Wheelwright NT et al (2009) Complexity in relationships between antioxidants and individual life-history parameters in a seabird and a songbird. Oikos 118:1854-1861. https://doi.org/10.1111/j.1600-0706.2009.17785.x

Dias MP, Granadeiro JP, Catry P (2013) Individual variability in the migratory path and stopovers of a long-distance pelagic migrant. Anim Behav. https://doi.org/10.1016/j.anbehav.2013.05.026

Dias MP, Granadeiro JP, Catry P (2012a) Working the day or the night shift? Foraging schedules of Cory's shearwaters vary according to marine habitat. Mar Ecol Prog Ser 467:245-252. https://doi. org/10.3354/meps09966

Dias MP, Granadeiro JP, Catry P (2012b) Do seabirds differ from other migrants in their travel arrangements? On route strategies of Cory's Shearwater during its trans-equatorial journey. PLoS ONE 7:e49376. https://doi.org/10.1371/journal.pone.0049376

Dias MP, Granadeiro JP, Phillips RA et al (2011) Breaking the routine: individual Cory's shearwaters shift winter destinations between hemispheres and across ocean basins. Proc R Soc B Biol Sci 278:1786-1793. https://doi.org/10.1098/rspb.2010.2114 
Fayet AL, Freeman R, Shoji A et al (2016) Carry-over effects on the annual cycle of a migratory seabird: an experimental study. J Anim Ecol 85:1516-1527. https://doi.org/10.1111/1365-2656.12580

Gilmour ME, Lattin CR, Romero LM et al (2014) Finding the best predictor of reproductive performance of Leach's Storm-Petrels. Auk 132:191-205. https://doi.org/10.1642/auk-14-21.1

Gómez-Díaz E, Navarro J, González-Solís J (2008) Ectoparasite community structure on three closely related seabird hosts: a multiscale approach combining ecological and genetic data. Ecography (Cop) 31:477-489. https://doi.org/10.111 1/j.0906-7590.2008.05330.x

Granadeiro JP, Dias MP, Rebelo R et al (2006) Numbers and population trends of Cory's Shearwater Calonectris diomedea at Selvagem Grande, Northeast Atlantic. Waterbirds 29:56-60. https://doi. org/10.1675/1524-4695(2006)29[56:naptoc]2.0.co;2

Green AJ (2001) Mass/length residuals: measures of body condition or generators of spurious results? Ecology 82:1473-1483. https:// doi.org/10.1890/0012-9658(2001)082[1473:MLRMOB]2.0.CO;2

Harrison XA, Blount JD, Inger R et al (2011) Carry-over effects as drivers of fitness differences in animals. J Anim Ecol 80:4-18. https://doi.org/10.1111/j.1365-2656.2010.01740.x

Hegemann A, Marra PP, Tieleman BI (2015) Causes and consequences of partial migration in a passerine bird. Am Nat 186:531-546. https://doi.org/10.1086/682667

Hegemann A, Matson KD, Both C, Tieleman BI (2012) Immune function in a free-living bird varies over the annual cycle, but seasonal patterns differ between years. Oecologia 170:605-618. https://doi. org/10.1007/s00442-012-2339-3

Hegemann A, Matson KD, Flinks H, Tieleman BI (2013) Offspring pay sooner, parents pay later: experimental manipulation of body mass reveals trade-offs between immune function, reproduction and survival. Front Zool. https://doi.org/10.1186/1742-9994-10-77

Inger R, Harrison XA, Ruxton GD et al (2010) Carry-over effects reveal reproductive costs in a long-distance migrant. J Anim Ecol 79:974-982. https://doi.org/10.1111/j.1365-2656.2010.01712.x

Jovani R, Rohwer S (2016) Fault bars in bird feathers: mechanisms, and ecological and evolutionary causes and consequences. Biol Rev 92:1113-1127. https://doi.org/10.1111/brv.12273

Koolhaas J, Korte S, De Boer S et al (1999) Coping styles in animals: current status in behavior and stress-physiology. Neurosci Biobehav Rev 23:925-935. https://doi.org/10.1016/S0149 -7634(99)00026-3

Lee KA (2006) Linking immune defenses and life history at the levels of the individual and the species. Integr Comp Biol 46:1000 1015. https://doi.org/10.1093/icb/ic1049

Matson KD, Horrocks NPC, Versteegh MA, Tieleman BI (2012) Baseline haptoglobin concentrations are repeatable and predictive of certain aspects of a subsequent experimentally-induced inflammatory response. Comp Biochem Physiol Part A Mol Integr Physiol 162:7-15. https://doi.org/10.1016/j.cbpa.2012.01.010

Matson KD, Ricklefs RE, Klasing KC (2005) A hemolysis-hemagglutination assay for characterizing constitutive innate humoral immunity in wild and domestic birds. Dev Comp Immunol 29:275-286. https://doi.org/10.1016/j.dci.2004.07.006

Møller AP, Szép T (2011) The role of parasites in ecology and evolution of migration and migratory connectivity. J Ornithol 152:1-10. https://doi.org/10.1007/s10336-010-0621-x

Mougin J-L, Jouanin C, Roux F (1997) Intermittent breeding in Cory's Shearwater Calonectris diomedea of Selvagem Grande, North
Atlantic. Ibis (Lond 1859) 139:40-44. https://doi.org/10.1111/ j.1474-919X.1997.tb04502.x

Nwaogu CJ, Cresswell W, Versteegh MA, Tieleman BI (2019) Seasonal differences in baseline innate immune function are better explained by environment than annual cycle stage in a year-round breeding tropical songbird. J Anim Ecol 88:537-553. https://doi. org/10.1111/1365-2656.12948

Owen-Ashley NT, Wingfield JC (2007) Acute phase responses of passerine birds: characterization and seasonal variation. J Ornithol 148:583-591. https://doi.org/10.1007/s10336-007-0197-2

Perez C, Granadeiro JP, Dias MP et al (2014) When males are more inclined to stay at home: insights into the partial migration of a pelagic seabird provided by geolocators and isotopes. Behav Ecol 25:313-319. https://doi.org/10.1093/beheco/art119

Pérez C, Granadeiro JP, Dias MP, Catry P (2016) Sex and migratory strategy influence corticosterone levels in winter-grown feathers, with positive breeding effects in a migratory pelagic seabird. Oecologia 181:1025-1033. https://doi.org/10.1007/s0044 2-016-3625-2

Péron C, Delord K, Phillips RA et al (2010) Seasonal variation in oceanographic habitat and behaviour of white-chinned petrels Procellaria aequinoctialis from Kerguelen Island. Mar Ecol Prog Ser 416:267-284. https://doi.org/10.3354/meps08785

R Core Team (2019) R: a language and environment for statistical computing. R Foundation for Statistical Computing, Vienna, Austria

Ramos JA, Monteiro LR, Sola E, Moniz Z (1997) Characteristics and competition for nest cavities in burrowing Procellariiformes. Condor 99:634-641. https://doi.org/10.2307/1370475

Ramos R, Llabrés V, Monclús L et al (2018) Costs of breeding are rapidly buffered and do not affect migratory behavior in a long-lived bird species. Ecology 99:2010-2024. https://doi.org/10.1002/ ecy. 2435

Ricklefs RE, Wikelski M (2002) The physiology/life-history nexus. Trends Ecol Evol 17:462-468. https://doi.org/10.1016/S0169 -5347(02)02578-8

Rowe L, Ludwig D, Schluter D (1994) Time, condition, and the seasonal decline of avian clutch size. Am Nat 143:698-722. https:// doi.org/10.2307/2462907

Santos ESA, Nakagawa S (2012) The costs of parental care: a metaanalysis of the trade-off between parental effort and survival in birds. J Evol Biol 25:1911-1917. https://doi.org/10.111 1/j.1420-9101.2012.02569.x

Selman C, Blount JD, Nussey DH, Speakman JR (2012) Oxidative damage, ageing, and life-history evolution: where now? Trends Ecol Evol 27:570-577. https://doi.org/10.1016/j.tree.2012.06.006

Sild E, Hõrak P (2009) Nitric oxide production: an easily measurable condition index for vertebrates. Behav Ecol Sociobiol 63:959_ 966. https://doi.org/10.1007/s00265-009-0710-0

Stearns SC (1992) The evolution of life histories. Oxford Univeristy Press, London

Versteegh MA, Helm B, Kleynhans EJ et al (2014) Genetic and phenotypically flexible components of seasonal variation in immune function. J Exp Biol 217:1510-1518. https://doi.org/10.1242/ jeb.097105

Zino PA, Zino F, Maul T, Biscoito JM (1987) The laying, incubation and fledging periods of Cory's Shearwater Calonectris diomedea borealis on Selvagem Grande in 1984. Ibis (Lond 1859) 129:393398. https://doi.org/10.1111/j.1474-919X.1987.tb03185.x 